Acest articol se citează:

Okros, N-I., (2015/2018). Agresivitatea, trăsăturile accentuate de personalitate, depresia și locul controlului la deținuții cu abuz de substanțe. Studia Doctoralia. Psychology and Educational Science, 9-10, 36-54.

\title{
AGRESIVITATEA, TRĂSĂTURILE ACCENTUATE DE PERSONALITATE, DEPRESIA ȘI LOCUL CONTROLULUI LA DEȚINUȚII CU ABUZ DE SUBSTANȚE
}

\author{
Okros Norberth-Ioan, Universitatea de Vest, Facultatea de Sociologie și \\ Psihologie \\ E-mail: okros_norberth@yahoo.com
}

\begin{abstract}
The purpose of this research is to highlight and analyze the psychological and judicial characteristics of inmates with substance abuse. The prisoners were divided into three groups: inmates with alcohol abuse $(n=30)$, inmates with drug abuse $(n=30)$ and inmates without substance abuse $(n=30)$. They were also divided into two categories: inmates convicted for offenses with violence against persons $(n=48)$ and inmates convicted for non-violent offenses $(n=$ 42). They completed a structured interview for diagnosing the major depressive episode and a series of psychometric tests for assessing aggression, personality traits, and locus of control. No significant differences between inmates with substance abuse and those without abuse in terms of aggression, nor between those convicted for crimes with violence against the person and those without violence against the person. It was found that there is a positive significant relationship between aggression and feature "Unrestrained" and between Locus of Control and the feature "Unrestrained". Finally, it has been found that there are differences between prisoners without depression regarding the type of offense, namely: prisoners with alcohol and without depression are prone to commit crimes with violence against persons and those with drug abuse, crimes without violence against persons.
\end{abstract}

Keywords: prisoners, alcohol abuse, drug abuse, aggression, personality traits, locus of control.

\section{Introducere}

Obiectivul studiului de față este de a evidenția și de a analiza caracteristicile psihologice ale persoanelor private de libertate $\mathrm{cu}$ abuz 
de substanțe, în comparație cu persoanele private de libertate fără abuz de substanțe.

Rațiunea alegerii acestui subiect se referă la faptul că majoritatea conceptelor la care am făcut referire aici au fost studiate separat sau deloc pe această categorie de subiecți. În țara noastră aceste aspecte nu au fost studiate, de aceea consider că această cercetare poate aduce un beneficiu sistemului penitenciar din România cu privire la dezvoltarea și conturarea unor viitoare programe de prevenție sau intervenție $\mathrm{cu}$ caracter psiho-social pentru acest mediu.

Această cercetare este importantă pentru psihologia judiciară deoarece reunește într-un singur studiu concepte care sunt considerate factori de risc în mediul penitenciar, precum: agresivitatea, abuzul de substanțe și depresia. Psihologii din acest sistem se confruntă zilnic în profesia lor cu acești factori de risc, pe care trebuie să îi identifice, să îi reducă, chiar să îi înlăture din viața psihologică a persoanei private de libertate. Este foarte importantă identificarea acestor factori de risc pentru adaptarea deținuților în penitenciare, iar mai apoi pentru reintegrarea lor în societate.

\section{Definirea conceptelor Agresivitatea}

De-a lungul anilor, conceptul de agresivitate a cunoscut foarte multe abordări și felurite definiții, fiind unul din cele mai studiate concepte. În mod tradițional, agresivitatea este văzută ca intenție de a răni o altă ființă vie (Baron \& Richardson, 1994, apud Anderson C.A., Bushman B.J., 2002). În abordarea behavioristă, agresivitatea este văzută ca răspuns care pur și simplu provoacă rău altora, un răspuns care implică stimuli nocivi către un alt organism. (Buss, 1961, apud Ramirez, J.M., Andreu, J.M., 2003). Agresivitatea este un fenomen foarte complex, fiind compusă dintr-un număr de alte comportamente specifice, iar din punct de vedere psihologic, biologic și evoluționist ea mai poate fi clasificată în șapte categorii (Moyer, 1968, apud Ramirez, J.M., Andreu, J.M., 2003).

De asemenea, s-a încercat să se clarifice aceste definiții, făcânduse referire la distincția între obiectivele apropiate și cele finale (Anderson \& Bushman, 2002). Intenția de a face rău unei persoane este văzută ca o 
caracteristică de bază în orice fel de agresiune. La nivelul ultimului scop, totuși, există o diferență clară între diferitele tipuri de agresiune. Astfel, atât jaful, cât și atacul fizic sunt acte de agresiune, deoarece ambele includ intenția de a răni victima. De obicei, acestea diferă în obiectivele finale, jafurile servind în primul rând scopurilor bazate pe profit și atacurile fizice care servesc în primul rând unor scopuri bazate pe rău. (Ramírez \& Andreu, 2006).

Agresivitatea mai poate fi legată și de consumul de substanțe (Boles \& Miotto, 2003), iar consumul de alcool și droguri este deseori întâlnit în rândul persoanelor care nu sunt violente (Fagan, 1990). Abuzul de substanțe, în principal abuzul de alcool, a fost deseori asociat timp de mai multe decenii cu comportamentele agresive, violente, dar cercetările au documentat rareori legăturile cauzale datorită variabilelor multiple care sunt implicate (Allen, Moeller, Rhoades, \& Cherek, 1997; Paglia \& Room, 1998, apud Boles \& Miotto, 2003). Prezența alcoolului sau a drogurilor în evenimente violente nu implică neapărat că aceste substanțe au influențat comportamentul fiecărui făptuitor sau victimă (Fagan, 1993a). În plus, substanțele diferite afectează indivizii în mod diferit, pe baza influenței fiziologiei, psihologiei, istoriei, sexului și a altor factori individuali și culturali (Collins, 1993).

\section{Trăsăturile accentuate de personalitate}

Trăsăturile accentuate de personalitate reprezintă al doilea concept folosit în studiul de față, concept dezvoltat de către neuropsihiatrul Karl Leonhard, în anul 1972. El a definit personalitatea accentuată ca o serie de însuşiri speciale care atunci când depășesc ca intensitate media, favorizează o puternică manifestare a acesteia (K. Leonhard, 1972). Cel mai mare avantaj al acestui model este că se referă la acele caracteristici particulare de personalitate care sunt mai evidențiate, mai conturate, fără a fi considerate dezadaptative. (Constantin, et al., 2010). Așadar, în viziunea lui K. Leonhard (1972) personalitatea accentuată este situată între normalitate și patologie psihică, într-o zonă nesigură deoarece este rezultatul a mai mulți factori educaționali, culturali, legați de experiența de viață, etc. 
Karl Leonhard, conform modelului său, propune următoarele trăsături accentuate ale personalității (K. Leonhard, 1972, apud Macarie A.E., 2007):

Firea demonstrativă - este definită print-o tendință de autocompătimire, empatie, laudă de sine, precum și grabă în luarea unor decizii.

Firea hiperexactă - este caracterizată de dificultăţi în luarea deciziilor, meticulozitate, o grijă excesivă care se manifestată prin verificări repetate, precum și ataşament față de locul de muncă.

Firea hiperperseverentă - este caracterizată atât în sens pozitiv, de ambiție, prestigiu personal, atingerea obiectivelor, dar și în sens negativ, de egoism, suspiciune, tendința de a se simți umilit.

Firea nestăpânită - dominată de impuls, individul fiind iritabil, uneori agresiv, capabil să comită acte ilicite sau violente, instabil în multiple aspecte ale vieții, acționând după sentimente, instincte.

Firea hipertimică - se caracterizează, în principal, printr-un surplus de energie şi se manifestă ca o combinaţie de veselie, optimism, cu dorinţa de a acţiona şi nevoia de a vorbi. $\mathrm{O}$ accentuare negativă duce spre agitaţie, superficialitate, iritabilitate, etc.

Firea distimică - caracterizează persoanele ca fiind extrem de serioase, cu principii etice ferme şi solide și o gândire mai lentă.

Firea labilă - apare ca o succesiune de stări pur hipertimice cu stări totalmente distimice. Evenimentele fericite nu produc numai bucurie normală, ci şi dorinţa de a acţiona şi de a vorbi, precum şi tendinţa către divagare în gândire. Evenimentele triste nu declanşează numai depresie, ci în acelaşi timp şi o încetinire în gândire şi acţiune.

Firea exaltată - reacționează mult mai intens la diferitele întâmplări, prin entuziasm sau disperare de cele mai multe ori, cauzele fiind mai degrabă nobile, superioare şi altruiste, decât egoiste. Frica şi grija pentru propria persoană pot deveni excesive. Se descurcă greu în viaţă, deoarece reacțiile lor deosebit de sensibile îi fac mai puţin apți să înfrunte dificultățile brutale ale existenței.

Firea anxioasă - adultul anxios este adesea timid şi docil, incapabil să se afirme în cazul divergențelor de opinie. Se poate produce însă şi o supracompensare, timiditatea exagerată având ca rezultat o atitudine aparent sigură de sine, plină de încredere sau chiar aroganță. 
Firea emotivă - se caracterizează prin reacţii de mare sensibilitate şi profunzime în sfera sentimentelor subtile. Trăirile emoţionale se exteriorizează prin expresivitatea mimicii (de exemplu, plâng la filme sau romane, la despărţiri sau revederi). Traumele psihice sunt greu suportate.

\section{Depresia}

Depresia este una dintre cele mai întâlnite probleme la deținuții din penitenciarele din România, ea fiind un factor de risc predominant în acest mediu. În anul 2007, dintr-un total de aproximativ 34,000 de persoane private de libertate, aproximativ 4,800 (13\%) dintre acestea erau diagnosticate cu o problemă de sănătate mintală (Popa, C., 2009). De asemenea, în anul 2013 în Penitenciarul de Maximă Siguranță din Arad, erau în evidența cabinetului medical de unitate un număr de 294 (29\%) de persoane private de libertate diagnosticate cu boli psihice, din care 151 de persoane erau în tratament medicamentos conform recomandărilor medicilor specialiști psihiatri, dintr-un total de 996 de persoane private de libertate. (ANP Arad, 2013).

\section{Locul Controlului}

Ultimul concept abordat în cadrul acestui studiu este Locul Controlului sau Locus of Control, concept introdus de către Julian B. Rotter în anul 1966, definit ca: „o expectanță generalizată cu privire la posibilitatea de a atinge obiectivele și țelurile dorite" (Rotter, 1966). Oamenii au tendința de a face o legătură între comportament și sistemul de întăriri, mai precis, oamenii justifică comportamentul personal sau al altei persoane, atribuind o anumită cauzaliatate, care poate fi internă sau externă. Astfel, persoanele care au un loc al controlului intern au o atribuire dispozițională internă, crezând că pot controla sursa pedepselor și recompenselor, iar persoanele cu un loc al controlului extern au o atribuire situațională externă, aceștia crezând că nu pot controla sursa pedepselor și recompenselor (Macsinga, I., 2015).

\section{Cercetări anterioare}

Literatura de specialitate din spațiul românesc este destul de săracă în privința cercetărilor pe acest subiect. Unul din argumente este 
faptul că pentru a desfășura un studiu în acest mediu strict, controlat și monitorizat, e nevoie de o mulțime de aprobări care, de obicei, necesită foarte mult timp pentru a fi verificate și pentru a primi permisiunea de a desfășura cercetarea. Al doilea argument este faptul că, în cazul sistemului penitenciar din România, majoritatea cercetărilor de acest fel sunt realizate, de obicei, de către psihologii din sistem, ele fiind disponibile într-un număr destul de mic pentru cei din exterior, asta datorită și nivelului de confidențialitate.

În spațiul internațional găsim numeroase studii realizate, dar niciunul nu include cumulat variabilele care reprezintă subiectul central al cercetării de față, ele fiind cercetate separat pe acest lot de participanți. În cazul relaţiei dintre agresivitate și consumul de substanțe, Fagan (1990) afirmă faptul că persoanele care nu sunt violente consumă alcool și droguri cel mai mult. Cu toate acestea, consumul de alcool, și într-o mică măsură, și consumul de droguri, sunt prezente atât în cazul infractorilor, cât și în rândul victimelor, în multe evenimente violente. În Statele Unite ale Americii, în anul 2006, în cazul infracțiunii de control, $37 \%$ din deținuții aflați în penitenciarele federale, de stat sau locale au comis infracțiuni de omor, viol, jaf sau agresiuni grave, iar dintre aceștia $77,5 \%$ au fost sub influența alcoolului sau a altor droguri în momentul comiterii faptei. Consumul de alcool este întâlnit în încarcerarea a peste jumătate ( 56,6 \% ) din toți deținuții din America, iar consumul ilicit de droguri este întâlnit în proporție de peste trei sferturi ( 75,9 \% ) (Behind bars II: substance abuse and America's prison population., 2010). Consumul de alcool este mai frecvent asociat cu infracțiuni precum: omorul, violul decât orice altă substanţă, iar consumul de droguri ilicite este, de asemenea, legat de crimele comise cu violență, deși există relativ puține surse. Criminalii care folosesc droguri ilegale comit jafuri și infracțiuni cu violență mai frecvent decât criminalii care nu folosesc droguri și le comit în special în perioadele de consum în cantități mari (Boles, S. M., \& Miotto, K., 2003).

Astfel, emitem următoarele ipoteze:

H1. Există diferență între cele trei grupuri din punct de vedere al agresivității. 
H2. Persoanele condamnate pentru infracțiuni cu violență asupra persoanei sunt mai agresive decât cele condamnate pentru infracțiuni fără violență asupra persoanei.

În cazul locului de control, literatura de specialitate, arată faptul că persoanele cu abuz de substanțe înregistrează un nivel semnificativ mai mare în cazul locului de control extern, deoarece ei sunt mai influențați de părerile celorlalți, refuză să își asume responsabilitatea, au tendința de a da vina pe altcineva pentru greșelile lor (Niazi, R. S., Pervaiz, R., Minhas, F. A., \& Najam, N., 2005).

În ceea ce privește persoanele private de libertate $\mathrm{cu}$ abuz de substanțe, literatura de specialitate arată că în cazul acestora prezența episoadelor de tip depresiv este mai frecventă (Chiles, J. A., Von Cleve, E., Jemelka, R. P., \& Trupin, E. W., 1990, Bermúdez, E. C., Mendoza, M. R., Ruiz, E. R., Durand-Smith, A. L., \& Hernández, G. S., 2007).

Așadar, considerăm că:

H3. Există o diferență semnificativă din punct de vedere statistic între deținuții fără depresie în ceea ce privește tipul de infracțiune comisă.

Evidențierea aspectelor specifice referitoare la trăsăturile accentuate de personalitate nu a fost studiată în cadrul literaturii de specialitate în cazul persoanelor private de libertate.

În acest caz, avem două întrebări de cercetare:

Q1. Există o legătură între Agresivitate și Trăsătura Accentuată de Personalitate "Nestăpânit"?

Q2. Există o legătură între Locul Controlului / Locus of Control și Trăsătura Accentuată de Personalitate „Nestăpânit"?

\section{Aspecte metodologice}

\section{Design-ul de cercetare}

Studiul de față are un design comparativ factorial de tipul 3 × 2 (Tabel 1), precum și aspecte corelaționale. Prima variabilă de tip independent are trei niveluri și reprezintă abuzul de substanțe: primul grup este format din 30 de deținuti cu abuz de alcool, al doilea grup este compus din 30 de deținuți cu abuz de droguri, iar cel de-al treilea grup este format din 30 de deținuți fără abuz de substanțe. Cea de-a doua variabilă independentă are două niveluri și reprezintă infracțiunea, mai 
specific: primul nivel reprezintă deținuții condamnați pentru infracțiuni cu violență asupra persoanei, fiind în număr de 48, iar cel de-al doilea nivel reprezintă deținuții condamnați pentru infracțiuni fără violență asupra persoanei, reprezentând restul deținuților, în număr de 42.

Categorizarea infracțiunilor în acest studiu are următoarea structură: infracțiuni cu violență asupra persoanei, din această categorie făcând parte: omorul, tentativă de omor, loviri și alte violențe, tâlhăria, tâlhăria calificată, iar cele fără violență asupra persoanei sunt: înșelăciunea, conducerea fără permis, traficul de droguri, consumul de droguri, traficul de persoane, traficul cu minori, ultrajul, nerespectarea regimului armelor și muniților, conducere sub influența alcoolului și furtul.

Tabel 1. Design comparativ factorial de tip $3 \times 2$

\begin{tabular}{ccc}
\hline & $\begin{array}{c}\text { Infracțiuni cu violență } \\
\text { asupra persoanei }\end{array}$ & $\begin{array}{c}\text { Infracțiuni fără } \\
\text { violență asupra } \\
\text { persoanei }\end{array}$ \\
\hline $\begin{array}{c}\text { Cu abuz de alcool } \\
\text { Cu abuz de droguri } \\
\text { Fără abuz de } \\
\text { substanțe }\end{array}$ & 22 & 8 \\
\hline
\end{tabular}

\section{Participanţi}

Participanții sunt 90 de persoane private de libertate din Penitenciarul de Maximă Siguranță Arad, cu media vârstei $(M)=34.43$, abaterea standard (AS) $=10.17$. Aceștia sunt condamnați pentru infracțiuni precum: tâlhărie calificată, loviri și alte violențe, tentativă de omor, omor, furt, tâlhărie, înșelăciune, conducere fără permis, conducere sub influența alcoolului, trafic de droguri, consum de droguri, evaziune fiscală, trafic de persoane, trafic cu minori, ultraj, nerespectarea regimului armelor și munițiilor. Condamnările pe care trebuie să le execute personale private de libertate participante la acest studiu încep de la 1 an și 3 luni până la detențiunea pe viață, echivalată în această cercetare cu 99 de ani. 


\section{Instrumente}

Primul chestionar este "Chestionarul de Agresivitate Buss - Perry" (Aggression Questionnaire / $A Q$ / BPAQ), care reprezintă o prelucrare a Inventarului de ostilitate, un instrument folosit pe scară largă în anii 60, dezvoltat de A.H. Buss. Acesta este format din 29 de itemi cu răspuns tip scală Likert de la 1 la 5 și măsoară 4 subscale: "Agresivitatea fizică”, „Agresivitatea verbală”, „Furia” și „Ostilitatea” (Buss, A. H., \& Perry, M. P., 1992).

Pentru a măsura trăsăturile accentuate de personalitate a fost utilizat "Chestionarul de Tendințe Accentuate Schmieschek” realizat de H. Schmieschek (1970) fiind tradus, adaptat și experimentat pentru țara noastră în anul 1975 de către I. M. Nestor. Chestionarul cuprinde 88 de întrebări, prezentate amestecat, formând zece grupe (I-X), fiecare grupă urmărind explorarea / evidenţierea unei anumite trăsături "accentuate" (Schmieschek, H. 1970).

Al treilea chestionar este „Locus of Control” dezvoltat de către Rotter în anul 1966. El cuprinde un număr de 29 de itemi dintre care doar 23 vizează direct Locul Controlului, ceilalți 6 itemi au fost incluşi de autor pentru a face mai ambiguu scopul testului. Fiecare item conţine două afirmații, unul referindu-se la locul controlului de tip intern, celălalt la locul controlului de tip extern. Participantul trebuie să aleagă din cele două afirmații cea care exprimă cel mai bine credința sa (Rotter, J. 1966).

Ultimul instrument folosit este "Mini-Interviul Neuropsihiatric Internațional, varianta 7.0.0" pentru DSM V, din cadrul căruia s-a folosit doar secțiunea destinată episodului depresiv major (Sheehan BV, Lecrubier Y, Sheehan KH, et al., 1998).

Primele trei chestionare sunt traduse și adaptate pe populaţie românească, precum și interviul structurat pentru care am primit aprobare spre a-l folosi de la autor.

\section{Procedura de cercetare}

Deținuții au fost testați în așa-numitele „cluburi”, reprezentând spații special amenajate pe fiecare secție, destinate pentru activități precum cele psihologice, educative și cele realizate de asistentul social. Ei au completat chestionarele în grupuri mici, formate din 5-7 deținuți. 
După ce intrau în sală, acestora li se prezenta scopul, obiectivele, și cum au fost ei selectați (dacă au consumat în exces alcool sau droguri), iar apoi le-a fost dat spre a citi și a semna un formular de consimțământ, unde erau precizate faptul că participarea la cercetare este benevolă, ei fiind chiar și răsplătiți cu 3 credite dacă participă, precum și anumite detalii referitoare la prezenta cercetare. Sistemul de credite este specific sistemului penitenciar, aceste credite cumulate aducând cu ele anumite beneficii. După completarea consimțământului, deținuților li s-a dat spre completare "Chestionarul de Agresivitate Buss - Perry", "Chestionarul de Tendințe Accentuate Schmiescheck" și "Chestionarul Locus of Control". La final, avea loc interviul structurat destinat diagnosticării episodului depresiv major, atât cel curent, cât și cel trecut. Acesta se realiza într-o altă încăpere cu fiecare deținut în parte pentru a se păstra confidențialitatea și intimitatea acestuia. Fiecare chestionar era însoțit de instrucțiuni scrise, cât și explicate verbal pentru o înțelegere cât mai acurată.

\section{Rezultate}

Prelucrarea datelor a fost realizată în SPSS 20, folosind tehnica de comparație ANOVA Factorială, Chi-Square, precum și corelația Pearson.

Testarea ipotezelor

1. Există diferență între cele 3 grupuri din punct de vedere al agresivității: $\mathrm{F}(2,84)=.173, \mathrm{p}>.05$. Prin urmare, nu s-au observat diferențe semnificativ statistic între cele 3 grupuri: abuz de alcool, abuz de droguri, fără abuz de substanțe, în privința agresivității. În tabelul 2 se pot vedea rezultatele obținute:

Tabel 2. Comparația între cele 3 grupuri în privința agresivității.

\begin{tabular}{rrrrrrrr} 
& \multicolumn{2}{c}{ Grupul 1 } & \multicolumn{2}{c}{ Grupul 2 } & \multicolumn{2}{c}{ Grupul 3 } \\
\hline & M & AS & M & AS & M & AS \\
\hline Agresivitate & 74.0 & 19.01 & 74.86 & 20.96 & 72.0 & 19.26 \\
\hline
\end{tabular}


2. Persoanele condamnate pentru infracțiuni cu violență asupra persoanei sunt mai agresive decât cele condamnate pentru infracțiuni fără violență asupra persoanei: $F(1,84)=.276, p>.05$. Nici în acest caz nu există diferențe semnificativ statistic între persoanele condamnate pentru infracțiuni cu violență asupra persoanei și cele condamnate pentru infracțiuni fără violență asupra persoanei, în privința agresivității, așadar ipoteza nu se confirmă. În tabelul 3 se pot vedea rezultatele obținute.

Tabel 3. Comparația între persoanele condamnate pentru infracțiuni cu violență asupra persoanei și cele condamnate pentru infracțiuni fără violență asupra persoanei, în privința agresivității

\section{Grupul 1}

Grupul 2

\begin{tabular}{ccccc}
\hline & M & AS & M & AS \\
\hline Agresivitate medii & 74.6 & 18.26 & 72.50 & 21.14 \\
\hline
\end{tabular}

De asemenea, nu există diferențe semnificativ statistic nici în cazul efectului de interacțiune dintre cele două variabile, și anume adicție și tipul de infracțiune: $F(2,84)=.015, p>$.05. În tabelul 4 se pot vedea rezultatele obținute.

Tabel 4. Efect de interacțiune între adicție și tipul de infracțiune

\begin{tabular}{|c|c|c|c|}
\hline \multirow[t]{4}{*}{$\begin{array}{c}\text { Fără } \\
\text { depresie }\end{array}$} & Adicție & Infracțiuni cu violență & $\begin{array}{c}\text { Infracțiun } \\
\text { fără } \\
\text { violență }\end{array}$ \\
\hline & Alcool & 16 & 5 \\
\hline & Drog & 9 & 14 \\
\hline & Control & 11 & 12 \\
\hline
\end{tabular}


3. Există o diferență semnificativă din punct de vedere statistic între deținuții fără depresie în ceea ce privește tipul de infracțiune comisă: $\varkappa 2(2, N=67)=6.556, p=.038<.05$. În acest caz ipoteza se confirmă. În tabelul 5 se pot vedea rezultatele obținute, iar în tabelul 6 se poate observa distribuirea deținuților fără depresie în funcție de adicție și tipul de infracțiune.

Tabel 5. Comparație între deținuții fără depresie în ceea ce privește tipul de infracțiune comisă

\begin{tabular}{ccc} 
& $\varkappa 2$ & $\mathrm{P}$ \\
\hline Fără depresie & 6.556 & .038 \\
\hline
\end{tabular}

Intrebări de cercetare

Există o legătură între agresivitate și trăsătura accentuată de personalitate "nestăpânit”: $\mathrm{r}(88)=.557, \mathrm{p}<.01$. Prin urmare, există o legătură semnificativ statistic între agresivitate și trăsătura accentuată de personalitate "nestăpânit”.

În tabelul 6 se pot vedea rezultatele obținute:

Tabel 6. Corelație între agresivitate și trăsătura accentuată de personalitate „nestăpânit”.

\begin{tabular}{llll}
\hline "Nestăpânit” & $\mathrm{R}$ & $\mathrm{P}$ & $\mathrm{r}^{2}$ \\
Agresivitate & .557 & $<.01$ & .31 \\
Agresivitate fizică & .425 & $<.01$ & .18 \\
Agresivitate verbal & .335 & $<.01$ & .11 \\
Furie & .518 & $<.01$ & .26 \\
Ostilitate & .465 & $<.01$ & .21 \\
\hline
\end{tabular}


2. Există o legătură între Locus of Control și trăsătura accentuată de personalitate „"nestăpânit”: $r(88)=.30, \mathrm{p}<.01$. Așadar, există o legătură semnificativă statistic între Locus of Control și trăsătura accentuată de personalitate „nestăpânit”. Este important de specificat faptul că pentru acest eșantion, predomină locusul de tip intern, media grupului fiind: $(\mathrm{M})=9.24$. În tabelul 7 se pot vedea rezultatele obținute:

Tabel 7. Corelație între locus of control și trăsătura accentuată de personalitate „nestăpânit”.

\begin{tabular}{cccc} 
& „Nestăpânit” & $\mathrm{r}^{2}$ & $\mathrm{p}$ \\
\hline Locus of Control & .30 & .09 & .003 \\
\hline
\end{tabular}

Prin urmare, ipotezele comparative 1 și 2 nu au susținere statistică, ceea ce înseamnă că nu există diferențe semnificativ statistic, în privința agresivității, nici între cele 3 grupuri, nici între deținuții condamnați pentru infracțiuni cu violență asupra persoanei și cei fără violenţă asupra persoanei. În cazul ipotezei comparativ 3, se observă o difernță semnificativ statistică între deținuții fără depresie. În privința agresivității, mai exact deținuții cu abuz de alcool au comis mai multe infracțiuni cu violență asupra persoanei, iar cei cu abuz de droguri au comis mai multe infracțiuni fără violență asupra persoanei. Ipoteze de tip corelațional 1 și 2 arată o legătură semnificativ statistică între locus of control și „nestăpânit” cu agresivitatea.

\section{Discuții}

Numeroasele studii privind agresivitatea în rândul deținuților cu abuz de substanțe demonstrează faptul că există o legătură între agresivitate și abuzul de substanțe (e.g., 2008; Paglia, A., \& Room, R., 1998; Haggård-Grann, U., Hallqvist, J., Långström, N., \& Möller, J., 2006; Boles, S. M., \& Miotto, K., 2003), dar doar de puține ori au fost documentate legături cauzale (Allen, Moeller, Rhoades, \& Cherek, 1997; Paglia \& Room, 1998). De asemenea, substanțele diferite afectează indivizii în mod diferit, pe baza fiziologiei, psihologiei, istoriei, sexului și a altor factori individuali și culturali (Collins, 1993). Consumul de 
alcool este mai frecvent asociat $\mathrm{cu}$ infracțiuni precum: omorul, violul decât orice altă substanță, iar consumul de droguri ilicite este, de asemenea, legat de crimele cu violență, deși există relativ puține surse. Criminalii care folosesc droguri ilegale comit jafuri și infracțiuni cu violență mai frecvent decât criminali care nu folosesc droguri și le comit în special în perioadele de consum în cantități mari de droguri (Boles, S. M., \& Miotto, K., 2003). Prin urmare, această legătură este evidențiată, dar trebuie să fim atenți la mai multe aspecte bio-psiho-socio-culturale.

În ceea ce privește persoanele private de libertate $\mathrm{cu}$ abuz de substanțe, literatura de specialitate arată că în cazul acestora prezența episoadelor de depresie este mai frecventă (Chiles, J. A., Von Cleve, E., Jemelka, R. P., \& Trupin, E. W., 1990, Bermúdez, E. C., Mendoza, M. R., Ruiz, E. R., Durand-Smith, A. L., \& Hernández, G. S., 2007). În cercetarea de față persoanele private de libertate nu prezintă episoade depresive majore într-un număr foarte mare. Sunt puțini deținuți identificați ca având episoade depresive majore. De asemenea, am observat faptul că deținuții cu abuz de alcool și fără depresie sunt predispuși să comită infracțiuni cu violență asupra persoanei, iar cei cu abuz de droguri, infracțiuni fără violentă asupra persoanei, prin ipoteza de tip comparativ 3, ea fiind confirmată și de către literatura de specialitate. Boles, S. M., \& Miotto, K. (2003) descoperă următorul lucru, consumul de alcool este mai frecvent asociat cu infracțiuni precum: omorul, violul decât orice altă substanță, iar consumul de droguri ilicite este, de asemenea, legat de crimele de violență, deși există relativ puține surse.

Într-o cercetare privind locul controlului Niazi, R. S., Pervaiz, R., Minhas, F. A., \& Najam, N., (2005), arată faptul că persoanele cu abuz de substanțe înregistrează un nivel semnificativ mai mare în cazul locului de control extern, deoarece ei sunt mai influențați de părerile celorlalți, refuză să își asume responsabilitatea, au tendința de a da vina pe altcineva pentru greșelile lor. Ipoteza de tip corelațional 2, privind legătura dintre locus of control și trăsătura „Nestăpânit” fiind astfel explicată. Persoanele cu un locus of control de tip extern refuză să își asume responsabilitatea, dau vina pe altcineva, iar cei cu trăsătura „Nestăpânit” sunt dominați de impuls, sunt agresivi și capabili să comită uneori acte ilicite sau violente, ei acționând după sentimente sau instincte. Ipoteza de tip corelațional 1, prin care se demonstrează relația 
dintre agresivitate și trăsătura accentuată de personalitate „Nestăpânit” este și ea susținută încă din definiția și caracteristicile persoanelor cu această trăsătură.

În urma rezultatelor obținute, ipotezele de tip comparativ 1 și 2 nu sunt susținute statistic, nefiind descoperite diferențe semnificative între grupuri privind agresivitatea. Acest lucru poate fi datorat regimului de detenție, închis și maximă siguranță, regim în care nivelul de agresivitate este mai crescut, iar deținuții ajung în acest regim datorită infracțiunilor violente sau din cauza comportamentului lor agresiv de-a lungul executării pedepsei. De asemenea, aceștia sunt obișnuiți cu astfel de chestionare. Nu în ultimul rând, neavând acces la rapoartele de incident, aceștia puteau răspunde la întrebările despre agresivitate într-un mod dezirabil, fiind și în grupuri mici de 5-7 persoane.

O astfel de cercetare are aplicabilitate în primul rând în psihologia judiciară, psihologia penitenciară și, nu în ultimul rând, psihologia socială, chiar și psihologia personalității.

\section{Limite și direcții viitoare}

O primă limită a acestui studiu este în cazul „Chestionarului de tendințe accentuate". și anume faptul că are o consistență internă foarte mică, fapt dovedit și de către studiul realizat de Constantin, et al., (2010). Și în acest caz, doar scalele pentru trăsăturile accentuate de personalitate „nestăpânit” și „,anxios" au obținut un coeficient de cosistență internă acceptabil pentru acest timp de studiu.

Acest studiu nu este unul cauzal, care să determine care este cauza pentru care persoanele $\mathrm{cu}$ abuz de substanțe sunt sau nu mai agresive decăt cele fără abuz sau la nivelul infracțiunilor comise, el arătând doar dacă există anumite diferențe între aceștia. De asemenea, rezultatele studiului nu pot fi generalizate pentru întreaga populație deoarece cercetarea are un număr mic de participanți.

În viitor, ar putea fi realizată o cercetare asemănătoare pe un eșantion mai mare de participanți. De asemenea, viitoarea cercetare să fie una de tip experimental pentru evaluarea cauzelor care duc la agresivitate în urma consumului de substanțe. $\mathrm{O}$ altă sugestie ar fi să se folosească un chestionar validat pe populațe românească și cu o 
consistență internă foarte bună pentru identificarea personalității deținuților, astfel conturându-se un profil de personalitate al abuzatorilor de substanțe care comit infracțiuni. Nu în ultimul rând, în cazul agresivității ar trebui colectate și alte date, ca de exemplu: rapoartele de incident care să fie coroborate cu rezultatele de la chestionar.

Concluzionând, persoanele private de libertate cu abuz de substanțe constituie un grup vulnerabil care nu trebuie ignorat, ci mai degrabă trebuie centrat în programe speciale pentru a crește confortul psihologic al acestora în urma opririi bruște a consumului de substanțe, datorită condamnării și încarcerării. De asemenea, trebuie dezvoltate programe personalizate pentru acest grup de persoane pentru scăderea agresivității.

\section{Bibliografie}

Allen, T. J., Moeller, F. G., Rhoades, H. M., \& Cherek, D. R. (1997). Subjects with a history of drug dependence are more aggressive than subjects with no drug use history. Drug and Alcohol Dependence, 46(1-2), 95-103

Anderson C.A., Bushman B.J., (2002). Human aggression. Annual Review of Psychology, 53:27-51.

Behind bars II: substance abuse and America's prison population. (2010). New York, NY: National Center on Addiction and Substance Abuse at Columbia University.

Bermúdez, E. C., Mendoza, M. R., Ruiz, E. R., Durand-Smith, A. L., \& Hernández, G. S. (2007). Female depression and substance dependence in the Mexico City penitentiary system. Salud Mental, 30(6), 53.

Boles, S. M., \& Miotto, K. (2003). Substance abuse and violence: A review of the literature. Aggression and violent behavior, 8(2), 155-174.

Buss, A.H. si Perry, M. (1992). The Aggression Questionnaire, Journal of Personality and Social Psychology, 63, 452-459. 
Chiles, J. A., Von Cleve, E., Jemelka, R. P., \& Trupin, E. W. (1990). Substance abuse and psychiatric disorders in prison inmates. Psychiatric Services, 41(10), 1132-1134.

Collins, J. J., \& Schlenger, W. E. (1988). Acute and chronic effects of alcohol use on violence. Journal of Studies on Alcohol, 49(6), 516-521

Collins, J. J. (1993). Drinking and violence: an individual offender focus. In S. E. Martin (Ed.), Alcohol and interpersonal violence: fostering multidisciplinary perspectives (pp. 221 - 236). Rockville, MD: US Department of Health and Human Services, Public Health Service, National Institutes of Health, National Institute on Alcohol Abuse and Alcoholism

Constantin, et al., (2010) - Caracteristici psihometrice ale Chestionarului D.A. 307 - „Dimensiuni Accentuate”, varianta 3.07 în Revista "Psihologia Resurselor Umane", vol 8, nr. 1/ 2010 (revista indexata PsychINFO şi CNCSIS), (pp. $62-74) . p p 10-26$

Cuomo, C., Sarchiapone, M., Giannantonio, M. D., Mancini, M., \& Roy, A. (2008). Aggression, Impulsivity, Personality Traits, and Childhood Trauma of Prisoners with Substance Abuse and Addiction. The American Journal of Drug and Alcohol Abuse, 34(3), 339-345.

Fagan, J. (1990). Intoxication and aggression. Crime and justice, 13, 241-320.

Fagan, J. (1993b). Interactions among drugs, alcohol, and violence. Health Affairs, 12(4), 65-79.

Haggård-Grann, U., Hallqvist, J., Långström, N., \& Möller, J. (2006). The role of alcohol and drugs in triggering criminal violence: a case-crossover study. Addiction, 101(1), 100-108.

Leonhard, K., (1972), Personalitati accentuate în viață și în literatură, Editura Enciclopedică Română, Bucureşti.

Macarie A.E. (2007) Personalitatea accentuată şi polii extremi ai stimei de sine. Volumul concursului "Studenţii cercetători au cuvântul" 
Macsinga, I. (2015). Psihologia diferențiala a personalității - Ed. revizuită. Editura de Vest, Timișoara

Moeller, F. G., \& Dougherty, D. M. (2001). Antisocial personality disorder, alcohol, and aggression. Alcohol research $\mathcal{E}$ health: the journal of the National Institute on Alcohol Abuse and Alcoholism, 25(1), 5-11.

Niazi, R. S., Pervaiz, R., Minhas, F. A., \& Najam, N. (2005). Locus of control and personality traits of male substance abusers and non abusers. Journal of Pakistan Psychiatric Society, 2(1), 41-44.

Popa, C. (2009). Mental health in Romanian prisons. PROBATION junior, 1(1), 82-107.

Paglia, A., \& Room, R. (1998). Alcohol and aggression: General population views about causation and responsibility. Journal of Substance Abuse, 10(2), 199-216.

Ramirez, J.M., Andreu, J.M. (2003). Aggression's typologies. International Review of Social Psychology, 16:145-161.

Ramírez, J., \& Andreu, J. (2006). Aggression, and some related psychological constructs (anger, hostility, and impulsivity) Some comments from a research project. Neuroscience \& Biobehavioral Reviews, 30(3), 276-291..

Rotter, J. (1966) 'Generalized expectancies for internal versus external control of reinforcement', Psychological Monographs 80 (1), 1-28)

Sheehan DV, Lecrubier Y, Harnett-Sheehan K, Amorim P, Janavs J, Weiller E, Hergueta T, Baker R, Dunbar G: The Mini International Neuropsychiatric Interview (M.I.N.I.): The Development and Validation of a Structured Diagnostic Psychiatric Interview. J. Clin Psychiatry, 1998;59 (suppl 20): 22-33.

Schmieschek, H. (1970). Questionnaire for the determination of accentuated personalities, Psychiatrie, Neurologie und Medizinische Psychologie, 22(10), 378-381. 
Wieczorek, W. F., Welte, J. W., \& Abel, E. L. (1990). Alcohol, drugs and murder: A study of convicted homicide offenders. Journal of Criminal Justice, 18(3), 217-227.

Zhang, L., Welte, J. W., \& Wieczorek, W. W. (2002). The Role Of AggressionRelated Alcohol Expectancies In Explaining The Link Between Alcohol And Violent Behavior. Substance Use \& Misuse, 37(4), 457-471. 